\title{
QT Dispersion and Electrocardiographic Changes in Women With Gestational Diabetes Mellitus
}

\author{
E. MEDOVÁ ${ }^{1}$, E. FIALOVÁ ${ }^{2}$, M. MLČEK ${ }^{2}$, J. SLAVÍČEK $^{2}$, A. DOHNALOVÁ ${ }^{2}$, \\ J. CHARVÁT ${ }^{3}$, E. ŽÁKOVIČOVÁ ${ }^{4}, O$. KITTNAR ${ }^{2}$
}

${ }^{1}$ Department of Anaesthesiology and Intensive Care, and ${ }^{2}$ Institute of Physiology, First Medical Faculty, Charles University, Prague, Czech Republic, ${ }^{3}$ Department of Internal Medicine, Second Medical Faculty, Charles University, Prague, Czech Republic, ${ }^{4} \mathrm{NsP}$ Medissimo, Bratislava, Slovakia

Received March 20, 2012

Accepted June 27, 2012

\section{Summary}

Gestational diabetes mellitus (GDM) represents additional risks to both mother and infant. Moreover it increases a woman's risk of cardiovascular disease in the postpartum. The aim of our study was therefore to detect changes of both the QT dispersion and the electrical heart field that could be typical for GDM. Body surface potential maps were obtained using the Cardiac 112.2 device from 26 young women with GDM and 54 young healthy pregnant women in the 36th week of pregnancy. The same recordings were obtained from 18 healthy women in the same age (19-36 years). The average QT dispersion ( $\pm S D$ ) in women suffering from GDM was significantly higher $(107 \pm 25 \mathrm{~ms})$ both than in those with physiological pregnancy $(73 \pm 18 \mathrm{~ms})$ and than in the normal subjects $(34 \pm 12 \mathrm{~ms})(\mathrm{P}<0.001)$. Moreover we have found in GDM patients shorter QRS complex $82.0 \pm 6.8 \mathrm{~ms}$ vs. $89.5 \pm 8.2 \mathrm{~ms}$ in healthy pregnant women and $90.8 \pm 7.9 \mathrm{~ms}$ in the control group $(p=0.011)$, more horizontal electrical heart axis $\left[16.4 \pm 20.1^{\circ}\right.$ vs. $42.4 \pm 28.7^{\circ}$ and $74.6 \pm 39.2^{\circ}$ respectively $(P<0.05)]$ and lower some depolarization and repolarization amplitudes on isopotential and isointegral maps. According to these results we suppose that described electrocardiographic changes reflect a deterioration of the complete process of ventricular depolarization and repolarization in GDM.

\section{Key words}

QT dispersion • Electrocardiography • Gestational diabetes mellitus

\section{Corresponding author}

Otomar Kittnar, Institute of Physiology, $1^{\text {st }}$ Medical Faculty, Charles University, Albertov 5, 12800 Prague 2, Czech Republic. E-mail: okittnar@If1.cuni.cz

\section{Introduction}

Gestational diabetes mellitus (GDM) is defined as a disorder of glucose tolerance occurring during pregnancy, which spontaneously improves after delivery or until the end of puerperium. The incidence is about $4 \%$ of all pregnancies and it is the second most common endocrinological complication of pregnancy (following thyroid disorders). Its prevalence increases over last years and increasing numbers of women suffering from GDM correlate both with rising incidence of overweight and obesity in the population and increasing age of expectant mothers. Risk factors of GDM are overweight or obesity, expectant mother's age over 30 years, positive family history - GDM or type 2 diabetes (DM) in the history or currently in mothers or grandmothers, obstetric history with GDM, hypertension or preeclampsia in previous pregnancy, delivery of fetus with high birth weight, stillbirth or recurrent miscarriage (Riskin-Mashiah, 2009). Mothers with GDM have increasing risk of pregnancy complications, but also increased risk of some pathologies long after its termination. They have increased incidence of hypertension, preeclampsia, nephropathy, but they are also in the risk of both hypoand hyperglycemia and if decompensated also ketosis and ketoacidosis. Further during the women's life increased incidence of hypertension and metabolic syndrome was found in up to $40 \%$ up to 20 years following the occurrence of GDM (Retnakaran 2009). Risks for the fetus are not less serious. Higher glycaemia mainly in the third trimester leads to so called diabetic fetopathy - 
increased birth weight and organ macrosomia. Following the birth, the children are at risk of hypoglycemia, hyperbilirubinemia, polycytemia plus spasms or breathing difficulties can result from hypocalcemia and hypomagnesemia. Children are more often obese, have higher proportion of body fat and the risk of the onset of type $2 \mathrm{DM}$ and metabolic syndrome increases already during growing up.

The development of GDM occurs due to insulin resistance resulting from increasing amounts of "antiinsulin" hormones produced particularly by placenta, i.e. compounds decreasing the tissues' sensitivity to insulin during pregnancy (Jovanovic-Peterson and Peterson 1996). Insulin resistance occurs in all pregnant women at the beginning of the second trimester and progresses during the third trimester. Decreased sensitivity of cells to insulin is compensated by appropriate increase of insulin production. However, women with GDM cannot raise insulin secretion sufficiently and hyperglycemia occurs. According to many international studies, e.g. HAPO study (2009), there is a direct relationship between glycaemia and the risks for the mother and fetus.
GDM significantly increases a woman's risk not only of type 2 diabetes mellitus but also of cardiovascular disease in the postpartum (Sullivan et al. 2012). In our previous work we have found differences in some parameters of the electrical heart field in patients with diabetes mellitus in comparison to controls (Zdarska et al. 2007). While the association of gestational diabetes mellitus and abnormal glucose tolerance is beyond doubt, its associations with other cardiovascular disease risk factors in the offspring are less clearly established. Women with gestational diabetes mellitus have an enhanced cardiovascular risk factor profile at 3-months postpartum and an elevated risk of future cardiovascular disease, as compared to their peers (Retnakaran 2009). As the dispersion of the QT interval (QTd) seems to be a useful parameter in detecting repolarization abnormalities that can be responsible for rhythm disorders (Mirvis 1985, van de Loo et al. 1994, Cowan et al. 1988, Day et al. 1990, Hii et al. 1992, Hohnloser et al. 1993, Barr et al. 1994, Somberg et al. 1985, Sporton et al. 1997, Kittnar et al. 2004), we have tried to measure QTd in addition to other changes of the electrical heart field in women with GDM.

Table 1. Basic characteristics of the examined groups (mean values \pm standard deviations).

\begin{tabular}{lccc}
\hline & Group 1 GDM & Group 2 Pregnant & Group 3 Control \\
\hline Number & 26 & 54 & 18 \\
Age & $31.8 \pm 3.9 *$ & $28.4 \pm 4.7$ & $26.4 \pm 5.8$ \\
BMI before pregnancy & $25.2 \pm 3.6^{*}$ & $23.3 \pm 3.3$ & $21.7 \pm 2.9$ \\
\hline
\end{tabular}

$*$ means significant difference against control group $(p<0.05)$.

\section{Methods}

\section{Patients}

Electrocardiographic recordings were obtained from 3 groups (basic characteristics of the groups are in Table 1):

Group $1(G D M): 26$ pregnant women with GDM in $36^{\text {th }}$ week of pregnancy on average, with mean age 32 years (27-40), and with BMI of 25.2 before pregnancy. Positive family or personal history was present in 19 women and further diseases in 8 (hypothyroidism 4, anemia 4). The group consisted of 18 women with a diet and 8 with insulin. Patients were followed and managed by the Diabetic Centre of Faculty Hospital in Motol. Results showing the degree of diabetes compensation, such as glycohemoglobin, total cholesterol, lipids, CRP, cortisol, prolactin etc., and readings of blood pressure, were available.

Group 2 (Pregnant): 54 healthy non-obese women with physiologic pregnancy, examined in $36^{\text {th }}$ week on average (35-37), mean age 28 years (19-36).

Group 3 (Control): Control group of 18 healthy, non-pregnant women with mean age of 26 years (20-35).

A healthy person was defined for the purposes of this project according to the following findings and data: negative cardiological family and personal history, normal arterial blood pressure, normal glycaemia, normal cholesterolaemia, normal ECG, non-smoker, normal body weight, negative neurological and endocrinological personal history, no cardioactive medication. 


\section{Measurement}

The examination was realized at standard conditions, in all cases by only one investigating person in order to assure full compatibility and reproducibility of obtained results in all examined groups. Data acquisition was performed in the morning and examined women relaxed for a few minutes before the recordings were made. While examined they were asked to be still to avoid muscle movements.

Electrocardiographic and vectorcardiographic recordings were obtained simultaneously using the Cardiac 112.2 device (Kittnar and Mlcek 2010). QT interval was measured from 80 unipolar chest leads used for body surface potential mapping. QT interval was measured from the start of the Q wave to the end of the $\mathrm{T}$ wave, each QT interval was corrected for the patient's heart rate (QTc) using Bazett's formula (van de Loo et al. 1994). QT dispersion was then defined as the difference between the maximal and minimal QT interval in any of the leads measured. Accordingly, QTc dispersion was defined as the difference between maximal and minimal heart rate-corrected QT interval QTc.

\section{Data analysis}

For the processing of the electrocardiographic and vectorcardiographic data the computer program of the Cardiac 112.2 device was used. This program determines common wave onsets, offsets and amplitudes for all 95 leads on one representative beat. The set of all leads comprised: 12 standard ECG leads, 3 orthogonal Frank's vectorcardiographic leads and 80 regularly placed unipolar body surface leads (Kittnar and Stovicek 1993).

QT intervals were measured manually by a single observer from curves on the device screen. He used the cursor to indicate the start of the $\mathrm{Q}$ wave and the end of the $\mathrm{T}$ wave. The curves were presented on the screen in a measure corresponding to a paper speed of $50 \mathrm{~mm} / \mathrm{s}$ and a gain of $1 \mathrm{mV} / \mathrm{cm}$. To check the reproducibility of measurement we have assessed both intraobserver and interobserver variabilty. Statistical evaluation of the assessed data was performed using the nonparametric Mann-Whitney test.

\section{Results}

Reproducibility of the determination of QT dispersion was high in both intraobserver and interobserver comparisons. In absolute numbers, the difference between the first and second determination of QT dispersion in the same ECG tracing (intraobserver variability) ranged between 0 and $18 \mathrm{~ms}$, with an average value of $8 \pm 3 \mathrm{~ms}$. The values for interobserver variability varied between 0 and $21(9 \pm 5 \mathrm{~ms})$.

Table 2. Electrocardiographic parameters of the examined groups (mean values \pm standard deviations).

\begin{tabular}{|c|c|c|c|}
\hline & Group 1 GDM & Group 2 Pregnant & Group 3 Control \\
\hline Heart Rate $\left(\mathrm{min}^{-1}\right)$ & $92.07 \pm 14.69 * *$ & $93.24 \pm 17.41 * *$ & $75.21 \pm 11.46$ \\
\hline$P Q$ interval $(m s)$ & $124.7 \pm 19.5 *$ & $125.8 \pm 24.9 *$ & $149.5 \pm 19.3$ \\
\hline QRS interval (ms) & $82.0 \pm 6.8 *^{+}$ & $89.5 \pm 8.2$ & $90.8 \pm 7.9$ \\
\hline QT interval (ms) & $337.3 \pm 18.7 *$ & $337.5 \pm 19.6 *$ & $365.2 \pm 30.5$ \\
\hline QTc interval (ms) & $414.8 \pm 24.8$ & $417.1 \pm 28.9$ & $405.3 \pm 20.7$ \\
\hline QT dispersion (ms) & $107 \pm 25^{* *} *^{++}$ & $73 \pm 18 * *$ & $34 \pm 12$ \\
\hline QTc dispersion $(\mathrm{ms})$ & $116 \pm 31 * *++$ & $79 \pm 21 * *$ & $36 \pm 13$ \\
\hline Electrical heart axis (deg) & $16.4 \pm 20.1 *^{+}$ & $42.5 \pm 28.7$ & $74.6 \pm 39.2$ \\
\hline QRS-T space angle (deg) & $68.5 \pm 29.8 *^{+}$ & $37.8 \pm 22.1$ & $25.6 \pm 19.9$ \\
\hline
\end{tabular}

* means significant difference against control group $(p<0.05) .{ }^{* *}$ means significant difference against control group $(p<0.01) .{ }^{+}$means significant difference between GDM and Pregnant groups $(p<0.05) .{ }^{++}$means significant difference between GDM and Pregnant groups $(p<0.01)$.

The average QT dispersion $( \pm \mathrm{SD})$ in the control group was significantly lower $(34 \pm 12 \mathrm{~ms})$ than in women in the late period of pregnancy $(73 \pm 18 \mathrm{~ms})(\mathrm{P}<0.001)$ and also than in women with GDM $(107 \pm 17 \mathrm{~ms})$. Significant difference was proved between the pregnant group and GDM group as well $(\mathrm{P}<0.01)$. The results were very similar using rate corrected values with average QTc dispersion values. Significant differences were found also 
in the case of QRS complex duration, electrical heart axis and QRS-T space angle. All basic electrocardiographic parameters are summarized in the Table 2. Decreased amplitudes both in maximal and minimal depolarization and maximal repolarization values in women with GDM were found as well as decreased activation time (Table 3). Important parameters with statistically significant differences are in Figures 1-4.

Table 3. Maximal and minimal depolarization values, maximal repolarization values, and activation times of the examined groups (mean values \pm standard deviations).

\begin{tabular}{lccc}
\hline & Group 1 GDM & Group 2 Pregnant & Group 3 Control \\
\hline Max depolarization $(\mu \mathrm{V})$ & $904 \pm 190^{* *++}$ & $1420 \pm 240$ & $1571 \pm 257$ \\
Min depolarization $(\mu \mathrm{V})$ & $-1086 \pm 227^{*+}$ & $-1503 \pm 327$ & $-1488 \pm 259$ \\
Max repolarization $(\mu \mathrm{V})$ & $320 \pm 35^{*+}$ & $389 \pm 39$ & $397 \pm 36$ \\
Activation time $(\mathrm{ms})$ & $64.4 \pm 4.0^{*+}$ & $71.3 \pm 7.8$ & $70.6 \pm 5.6$ \\
\hline
\end{tabular}

* means significant difference against control group $(p<0.05) .{ }^{* *}$ means significant difference against control group $(p<0.01) .{ }^{+}$means significant difference between GDM and Pregnant groups $(p<0.05) .{ }^{++}$means significant difference between GDM and Pregnant groups $(p<0.01)$.

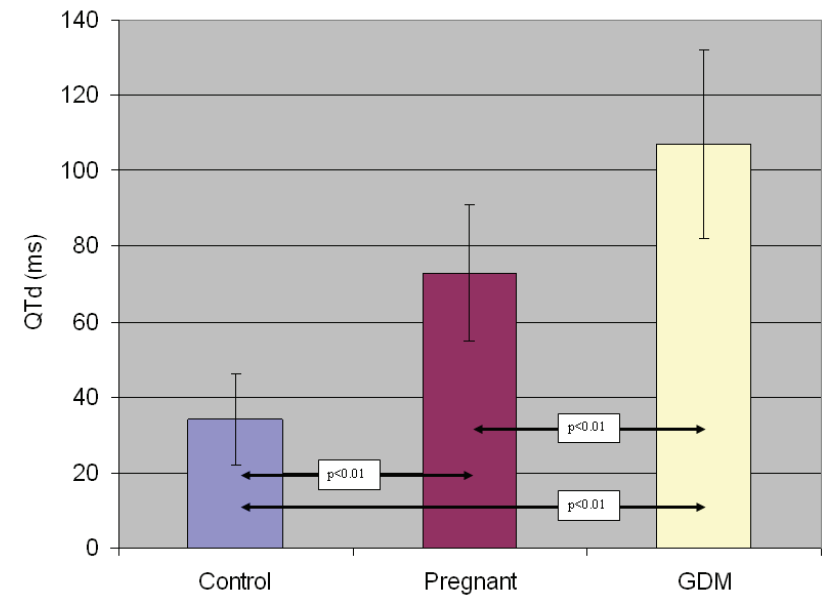

Fig. 1. Dispersion of the QT interval in examined groups (mean values $\pm S D)$.

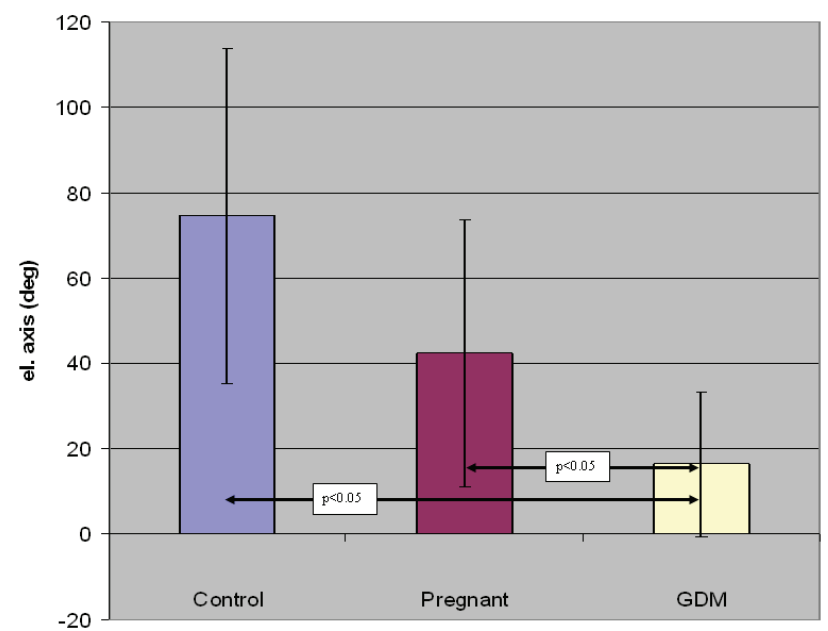

Fig. 3. Electrical heart axis in examined groups (mean values \pm $\mathrm{SD})$.

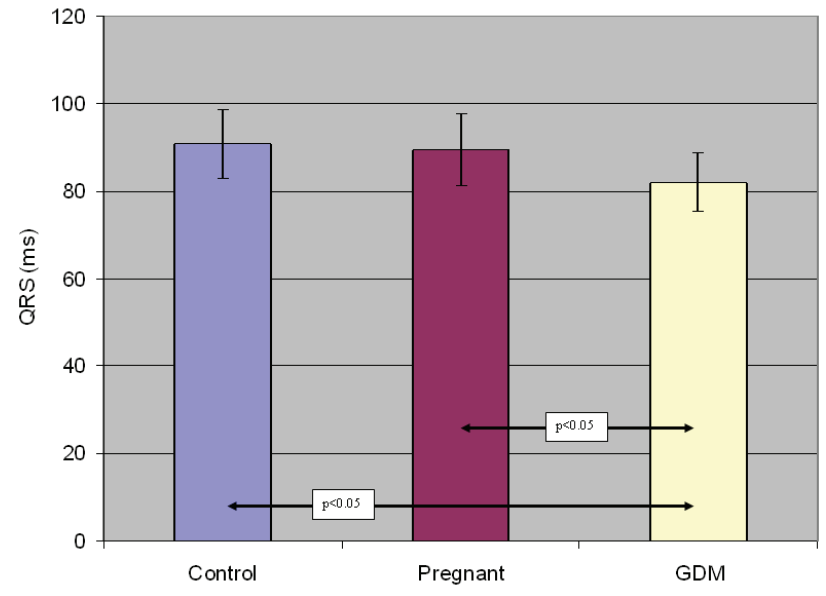

Fig. 2. QRS complex duration in examined groups (mean values $\pm \mathrm{SD})$.

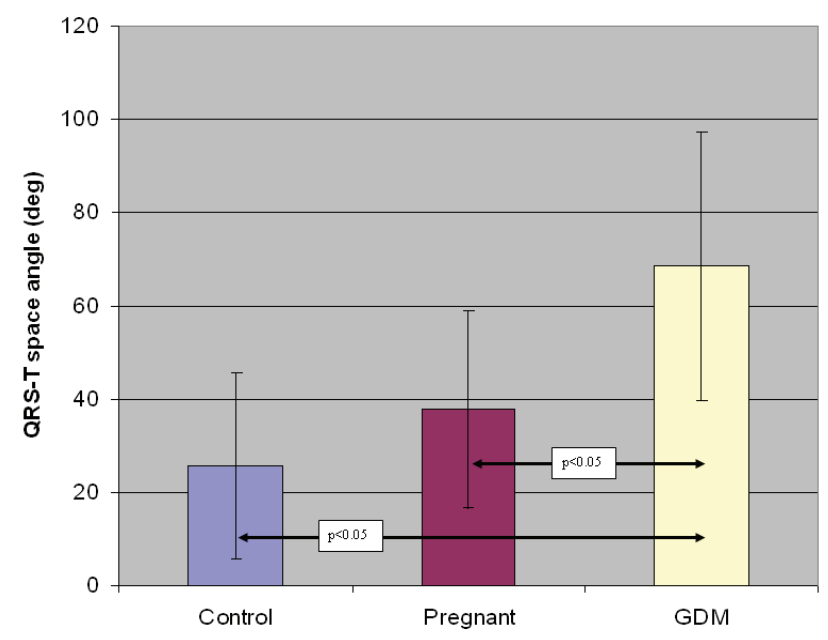

Fig. 4. Space angle QRS-T in examined groups (mean values \pm SD). 


\section{Discussion}

The present study aimed to determine the eventual changes in the dispersion of QT interval in the patients with GDM from ECG curves used the body surface potential mapping. Consideration of greater number of leads for determination of QT dispersion appears to determine QT dispersion more accurately than assessment in only 12 or even 6 precordial leads. The use of low number of leads was undoubtedly the main cause of repeatedly suggested poor reproducibility (Kautzner et al. 1994, Day et al. 1990). Enhanced accuracy for QT dispersion assessment from 12-lead ECG in comparison with only 6 precordial leads was reported as well (van de Loo et al. 1994, Higham and Campbell 1994). Moreover, the reproducibility could be influenced by the measure of the ECG curve (a paper speed and a gain) and especially lower time resolution $(25 \mathrm{~mm} / \mathrm{s})$ was suggested to be an important reason for poor reproducibility (Glancy et al. 1996). Both the intra- and interobserver variability of QT and QTc dispersion assessed in this study permits use of this method to determine changes in QT dispersion as the detected changes lie well above the errors encountered in this study.

Our previous results have suggested that the QT interval and QTd are changed both in the physiological late pregnancy (Lechmanova et al. 2002) and in the diabetes mellitus (Palova et al. 2010, Zdarska et al. 2007). We have concluded therefore that QT dispersion can reflect not only increased risk of serious tachyarrhythmias especially due to myocardial ischaemia but it must be interpreted simply just as "an unspecific sign of changed course of repolarization". The present study proved that QTd in the control group is significantly shorter than in physiological pregnancy and GDM. Moreover QTd was significantly prolonged in patients with GDM in comparison to the healthy pregnant women (the pregnant group). It can be interpreted that factors responsible for prolongation of QTd are added together.

Higher age and BMI in group with GDM in comparison to the control group were found. Nevertheless these differences cannot explain electrocardiographic changes: in one of our previous studies only a lower heart rate and a longer QT interval were found in older persons (Slavicek et al. 2001). In the present study the results were quite opposite in the GDM group (that is older than the control group). In a study focused on QT dispersion in obese patients increased QT dispersion was observed in patients with severe obesity with BMI higher than 35 (Mshui et al. 1999) what was not our case.

Shortened QRS interval in group with GDM in comparison to the other two groups corresponds to the shortening of the activation time in GDM patients. These findings are consistent with our previous results in type 1 diabetic patients (Palova et al. 2010). QT interval was prolonged both in GDM patients and healthy pregnant women but this was evidently due to increased heart rate as there were no significant differences of QTc among studied groups. Increased intraventricular conductance can be explained by activation of the sympathoadrenergic axis due to increased production of placental prolactin in the gestational diabetes mellitus (Newbern and Freemark 2011).

Horizontal electrical heart axis was found in all pregnant women and its direction differs significantly from the control group. Significantly more horizontal direction of the axis in women with GDM can be explained by increased size of fetus but we cannot exclude also remodelation of myocardium. This hypothesis is partially supported by increased QRS-T space angle in the group of GDM women. The opening of spatial angle between integral vectors of the QRS complex and $\mathrm{T}$ wave depends on the different depolarization and repolarization pattern (Pisvejcova et al. 2002) and can be related to a left ventricular overload or hypertrophy (Ruttkay-Nedecky 1983). Moreover it is an indicator of adrenergic tonization of the working myocardium (Andrasyova et al. 1998) what can contribute to the increased intraventricular conductance.

Decreased depolarization and repolarization amplitudes are most probably caused by the geometrical changes of the chest organs in the late pregnancy particularly by the increased content of lipid tissue between the heart and measuring electrodes.

One of the main limitations of this study is that the group of GDM patients is not fully consistent particularly as for their treatment: 8 of them were treated by insulin, 18 were just on a diet. On the other hand all of them were well compensated both as for glycaemia $(5.11 \pm 0.66 \mathrm{mmol} / \mathrm{l})$ and HbAlc $(28.6 \pm 0.31 \mathrm{mmol} / \mathrm{mol})$. Moreover 4 women from the GDM group were treated because of hypothyreosis but also these patients were fully compensated by pharmacological treatment.

The electrocardigraphic parameters were not so far systematically studied in spite of fact that GDM represents increased cardiovascular risk in the 
postpartum. Based on our results it can be concluded that there are at least functional changes in the electrical heart field in GDM patients that can contribute to the risk. Because of significant differences in comparison to the physiological pregnancy described affection of the electrical heart field cannot be explained just by the geometrical changes of the chest organs in the late pregnancy or by hormonal influence of gestational hormones but most probably other hormonal disturbances related to a deteriorated metabolic control in GDM women are responsible for these changes.

\section{Conflict of Interest}

There is no conflict of interest.

\section{Acknowledgements}

This work was supported by PRVOUK-P38/LF1/10 grant.

\section{References}

BARR CS, NAAS A, FREEMAN M, STRUTHERS AD: QT dispersion and sudden unexpected death in chronic heart failure. Lancet 343: 327-329, 1994.

COWAN JC, YUSOFF K, MOORE M, AMOS PA, GOLD AE, BOURKE JP, TANSUPHASWADIKUL S, CAMPBELL RW: Importance of lead selection in QT interval measurement. Am J Cardiol 61: 83-87, 1988.

DAY CP, MCCOMB JM, CAMPBELL RWF: QT dispersion: an indication of arrhythmia risk in patients with long QT intervals. Br Heart J 63: 342-344, 1990.

GLANCY JM, WESTON PJ, BHULLAR HK, GARRATT CJ, WOODS KL, DE BONO DP: Reproducibility and automatic measurement of QT dispersion. Eur Heart J 17: 1035-1039, 1996.

HAPO STUDY COOPERATIVE RESEARCH GROUP (METZGER BE ET AL.): Hyperglycemia and Adverse Pregnancy Outcome (HAPO) study. Associations with neonatal antropometrics. Diabetes 58: 453-459, 2009.

HIGHAM PD, CAMPBELL RWF: QT dispersion. Br Heart J 71: 508-510, 1994.

HOHNLOSER SH, VAN DE LOO A, KALUSCHE D, ARENDTS W, QUART B: Does sotalol-induced alteration of QT-dispersion predict drug effectiveness or proarrhythmic hazards? (abstract) Circulation 88 (Suppl I): I-397, 1993.

JOVANOVIC-PETERSON L, PETERSON CM: Vitamin and mineral deficiencies which may predispose to glucose intolerance of pregnancy. J Am Coll Nutr 15: 14-20, 1996.

KAUTZNER J, GANG YI, CAMM AJ, MALIK M: Short- and long-term reproducibility of QT, QTc and QT dispersion measurement in healthy subjects. PACE 17: 928-937, 1994.

KITTNAR O, MLCEK M: Analysis of the electrical heart field. Physiol Res 59 (Suppl 1): S19-S24, 2010.

KITTNAR O, STOVICEK P: Contemporary body surface potential mapping in electrocardiology and its perspectives. Physiol Res 42: 141-143, 1993.

KITTNAR O, PACLT I, MLCEK M, SLAVICEK J, DOHNALOVÁ A, HAVRANEK S, BRIZMAN E, KITZLEROVÁ E, PISVEJCOVA K: QT dispersion and electrical heart field morphology in patients treated with dosulepin. Physiol Res 53: 379-386, 2004.

LECHMANOVA M, KITTNAR O, MLCEK M, SLAVICEK J, DOHNALOVA A, HAVRÁNEK S, KOLARIK J, PAŘÍZEK A: QT dispersion and T-loop morphology in late pregnancy and after delivery. Physiol Res 51: 121$129,2002$.

MIRVIS DM: Spatial variation of the QT intervals in normal persons and patients with acute myocardial infarction. J Am Coll Cardiol 5: 625-631, 1985.

MSHUI ME, SAIKAWA T, ITO K, HARA M, SAKATA T: QT interval and QT dispersion before and after diet therapy in patients with simple obesity. Proc Soc Exp Biol Med 220: 133-138, 1999.

NEWBERN D, FREEMARK M: Placental hormones and the control of maternal metabolism and fetal growth. Curr Opin Endocrinol Diabetes Obes 18: 409-416, 2011.

PALOVA S, SZABO K, CHARVAT J, SLAVICEK J, MEDOVA E, MLCEK M, KITTNAR O: ECG body surface mapping changes in type 1 diabetic patients with and without autonomic neuropathy. Physiol Res 59: 203-209, 2010. 
PISVEJCOVA K, PACLT I, SLAVÍCEK J, KITTNAR O, DOHNALOVA A, KITZLEROVA E: Electrocardiogram, vectocardiogram and body surface maps in patients with panic disorder. Physiol Res 51: 401-406, 2002.

RETNAKARAN R, SHAH BR: Mild glucose intolerance in pregnancy and risk of cardiovascular disease: a populationbased cohorty study. C.M.A.J. 181: 371-376, 2009.

RISKIN-MASHIAH S, DAMTI A, YOUNES G, AUSLENDER R: First-trimester fasting hyperglycemia and adverse pregnancy outcomes. Diabetes Care 32: 1639-1643, 2009.

SLAVICEK J, KITTNAR O, NOVAK V, TREFNY Z, HORACEK BM: ECG body surface isointegral and isoarea maps (BSM) in 30 and 60-years-old healthy humans. Sb Lek 102: 369-374, 2001.

SOMBERG J, TEPPER D, WYNN J: Prolonged repolarisation: a historical perspective. Am Heart J 109: 395-398, 1985.

SPORTON SC, TAGGART P, SUTTON PM, WALKER JM, HARDMAN SM: Acute ischaemia: a dynamic influence on QT dispersion. Lancet 349: 306-309, 1997.

SULLIVAN SD, UMANS JG, RATNER R: Gestational diabetes: implications for cardiovascular health. Curr Diab Rep 12: 43-52, 2012.

VAN DE LOO A, ARENDTS W, HOHNLOSER SH: Variability of QT dispersion measurements in the surface electrocardiogram in patients with acute myocardial infarction and in normal subjects. Am J Cardiol 74: 11131118, 1994.

ZDARSKA D, PELISKOVA P, CHARVAT J, SLAVICEK J, MLCEK M, MEDOVA E, KITTNAR O: ECG body surface mapping (BSM) in type 1 diabetic patients. Physiol Res 56: 403-410, 2007. 